\title{
IS THE NUMBER OF DAYS WITH LIGHTNING CHANGING? A STUDY FOR SOUTHEASTERN EUROPE OF THE PERIOD 1980-2018
}

Article DOI: $\underline{\text { https://doi.org/10.35219/ann-ugal-math-phys-mec.2019.1.12 }}$

\author{
Radu Costin Pană ${ }^{1}$ \\ ${ }^{1}$ University of Bucharest, Faculty of Physics, Bucharest, Romania, email: rd_pana@yahoo.com
}

\begin{abstract}
Lightning is one of the leading causes of weather-related fatalities worldwide and also has a strong impact on atmospheric chemistry (i.e., NOx production). Lightning can also lead to power system breakdowns, ignite forest fires, damage wind turbine and lead to perturbation of transportation, in particular to aviation. Thus, knowing when, where lightning strike and which atmospheric environments are more frequently associated with lightning is important. Furthermore, given the increase in the population density in recent decades (i.e., more people are exposed to lightning) and the increased urbanization (i.e., cities are getting larger and thus are more exposed to lightning) is essential to understand the spatial and temporal distribution of storm producing lightning and their environments in the current climate and their changes in the past and coming decades. To address these issues, in this study we analyze the changes in the number of days with atmospheric conditions leading to lightning over southeastern Europe. Here we consider the noninductive charging mechanism as the main mechanism for cloud electrification. We search for ingredients supporting for this cloud electrification mechanism using a series of parameters (e.g., convective available potential energy, total precipitable water, heights of various isotherms) obtained from vertical profiles collected from radiosonde sites over southeastern Europe (e.g., Romania, Hungary, Bulgaria). This paper will present the changes between 1980 and 2018 in the number of days with condition supporting the occurrence of lightning in urban areas from southeastern Europe.
\end{abstract}

Keywords: lightning, climatology, atmospheric soundings.

\section{INTRODUCTION}

Lightning is one of the leading causes of weather-related fatalities worldwide and also has a strong impact on atmospheric chemistry (i.e., NOx production). Lightning can also lead to power system breakdowns, ignite forest fires, damage wind turbine and lead to perturbation of transportation in particular to aviation. Thus, knowing when, where lightning strike and which atmospheric environments are more frequently associated with lightning is important.

Most often, lightning is observed between specific types of clouds, such as cumulonimbus and soil, almost daily in the tropics, and temperate latitudes, mostly during the summer months. Very numerous flashes are also observed in volcanic eruptions, in which rising damp is probably not the 
cause in question. In both cases, it has not been possible to fully elucidate, which leads to the huge charge separation that must have taken place before.

What is puzzling is the obvious difference to laboratory experiments with gases, where it is difficult to generate and maintain charge separation without metallic conductors and insulators because of the good mobility of the molecules. A lightning occurrence is a potential equalization within the cloud (cloud lightning) or between the ground and the lower part of the cloud (earth lightning).

For lightning between the cloud and the earth, the potential difference (the voltage) must be tens of millions of volts. In the air, it only comes to an electric spark discharge at an electric field strength of about three million volts per meter (the so-called breakdown field strength); however, this value drops sharply with increasing humidity. However, such field strengths have never been measured in a storm cloud. Measurements only rarely result in field strengths of over $200,000 \mathrm{~V} / \mathrm{m}$, which is significantly below the breakthrough value. Therefore, it is now believed that the air must first be made conductive by ionization, so that it can come to a lightning discharge.

On average, four to five main discharges make a flash. The pre-discharges taken together take about 0.01 seconds, the main discharge lasts only $30 \mu \mathrm{s}(0.00003 \mathrm{~s})$. After a recovery break between $0.03 \mathrm{~s}$ and $0.05 \mathrm{~s}$, a new discharge takes place. Already up to 42 consecutive discharges have been observed. This causes the flickering of a lightning bolt. The current of a main discharge is about 20,000 amperes on average, whereby a strong magnetic field surrounds the flash channel [1].

The combination of current and magnetic field causes a compression of the conductive plasma channel (pinch effect), which has a diameter of only a few centimeters. At the point where the lightning goes into the ground (or out of it), a strong field of tension (high potential) forms, which decreases in a circular shape from the point of impact and continues in a conical shape in the ground. The area, depth and potential of the cone are, for example, dependent on the strength of the flash, the nature of the ground and moisture. In the center of the cone it can come to rock melting.

There are 2,000 to 3,000 thunderstorms worldwide at any given time, producing 10 to 30 million flashes a day across the globe acording to United States' National Oceanic and Atmospheric Administration (NOAA)'s National Environmental Satellite, Data, and Information Service division that supports weather forecasting, severe storm tracking, and meteorology research [2]. That's over 100 flashes every second. But only $10 \%$ of all lightning strikes the ground.

\section{INVESTIGATION}

In this paper, observed soundings characteristic of the preline environment are examined in order to evidentiate a day with potential lightning conditions. In order for production of a Cloud-toground (CG) process to appear there must be an electrical charge inside a cloud, meaning updraft associated with steep convective growth must happen inside the lower region of the cloud, where supercooled water and ice particles co-occur (Reynolds 1949, 1956, Michimoto 1993) [3][4][5].

Because the supercooled liquid water freezes at temperatures at approximately $-40^{\circ} \mathrm{C}$ depending on the types of ice nucleation and ice begins to form at temperatures between $-5^{\circ} \mathrm{C}$ and $10^{\circ} \mathrm{C}$, it is considered that the temperature of the mixed-phase part of the cloud to be between $-10^{\circ} \mathrm{C}$ and $-40^{\circ} \mathrm{C}$. Responsible for creating CG processes is the interaction between supercooled liquid water and ice in order to form snow pellets in the lower part of the cloud where mixed-phase occurs (Bryan 2000) [6].

Transpose to the actual data gathered from radiosonde sites over southeastern Europe (i.e., Romania, Hungary, Bulgaria) obtained from vertical profiles we must check using a series of parameters (e.g., convective available potential energy, total precipitable water, heights of various isotherms) if the following meteorological criteria are met: First and foremost, the convective available potential energy (CAPE) must be greater than $100-200 \mathrm{~J} \mathrm{~kg}^{-1}$ in the $0^{\circ}$ to $-20^{\circ} \mathrm{C}$ layer, in order to provide the necessary ascent for electrification. Second, the equilibrium level (EL) must be colder than $-20^{\circ} \mathrm{C}$, ensuring ice nucleation. And third, the lifting condensation level (LCL) must be warmer than $-10^{\circ} \mathrm{C}$, ensuring a low-level source of supercooled cloud water into the convective line.

These statements are supported by previous research like MacGorman and Rust 1998, Reynolds and Brook 1956, Michimoto 1991, 1993, or Workman and Reynolds 1949 and considered 
ideal for the lightning phenomena to occur [3][4][5][7][8].

\section{RESULTS}

Analyzing data and parameters during the period between 1980 and 2018 we present the following charts representing the number of days when CG conditions concurred.

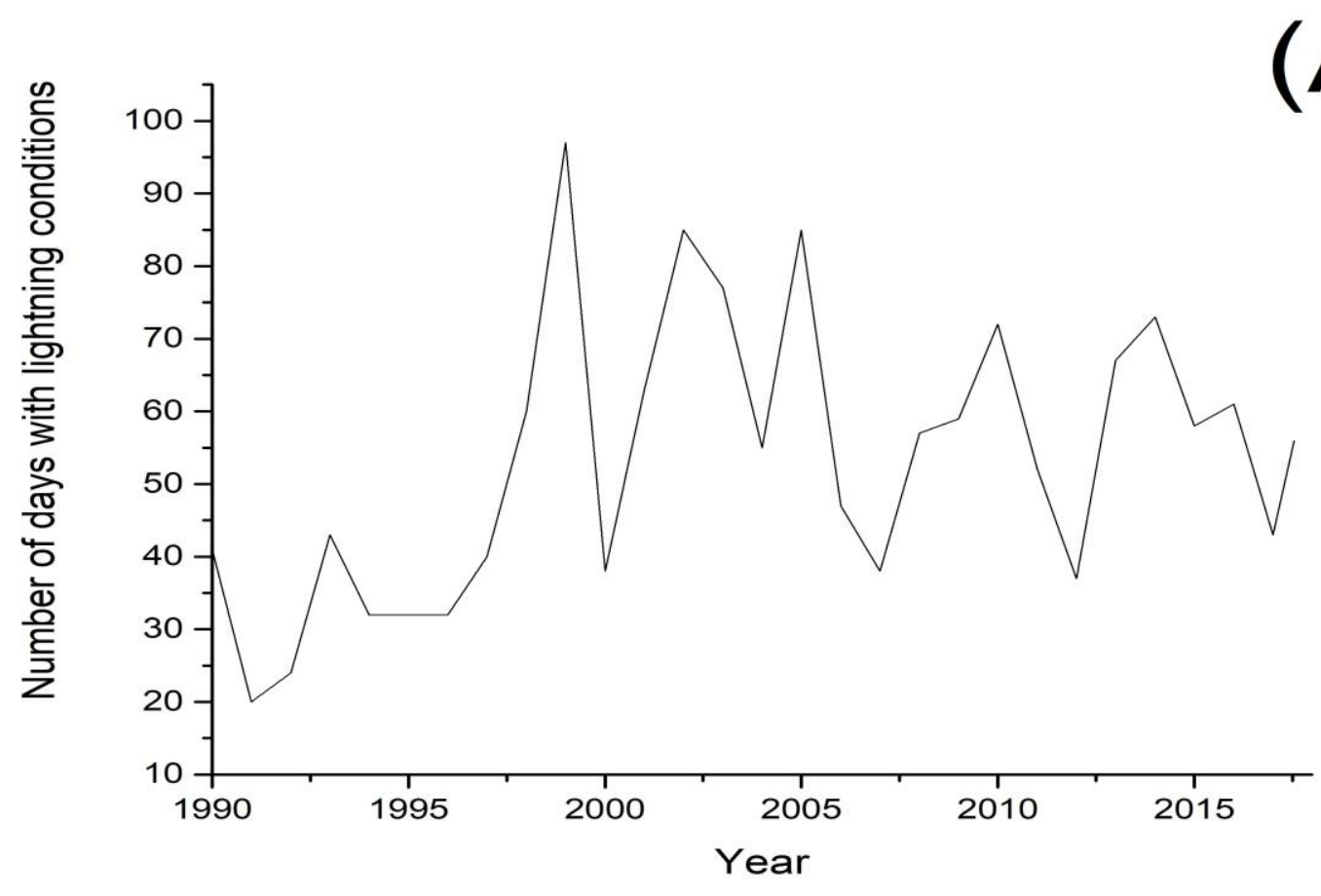

(B)

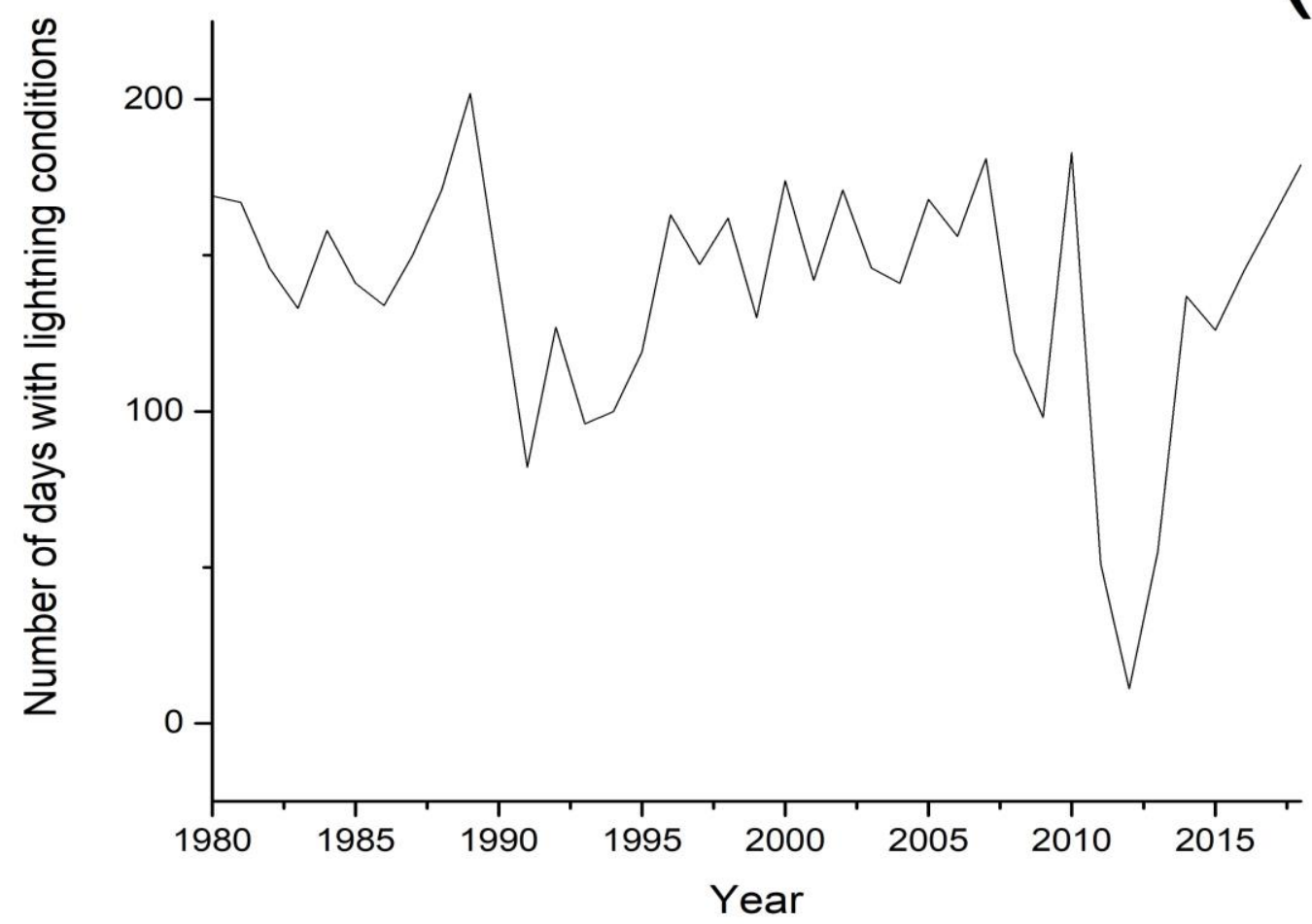




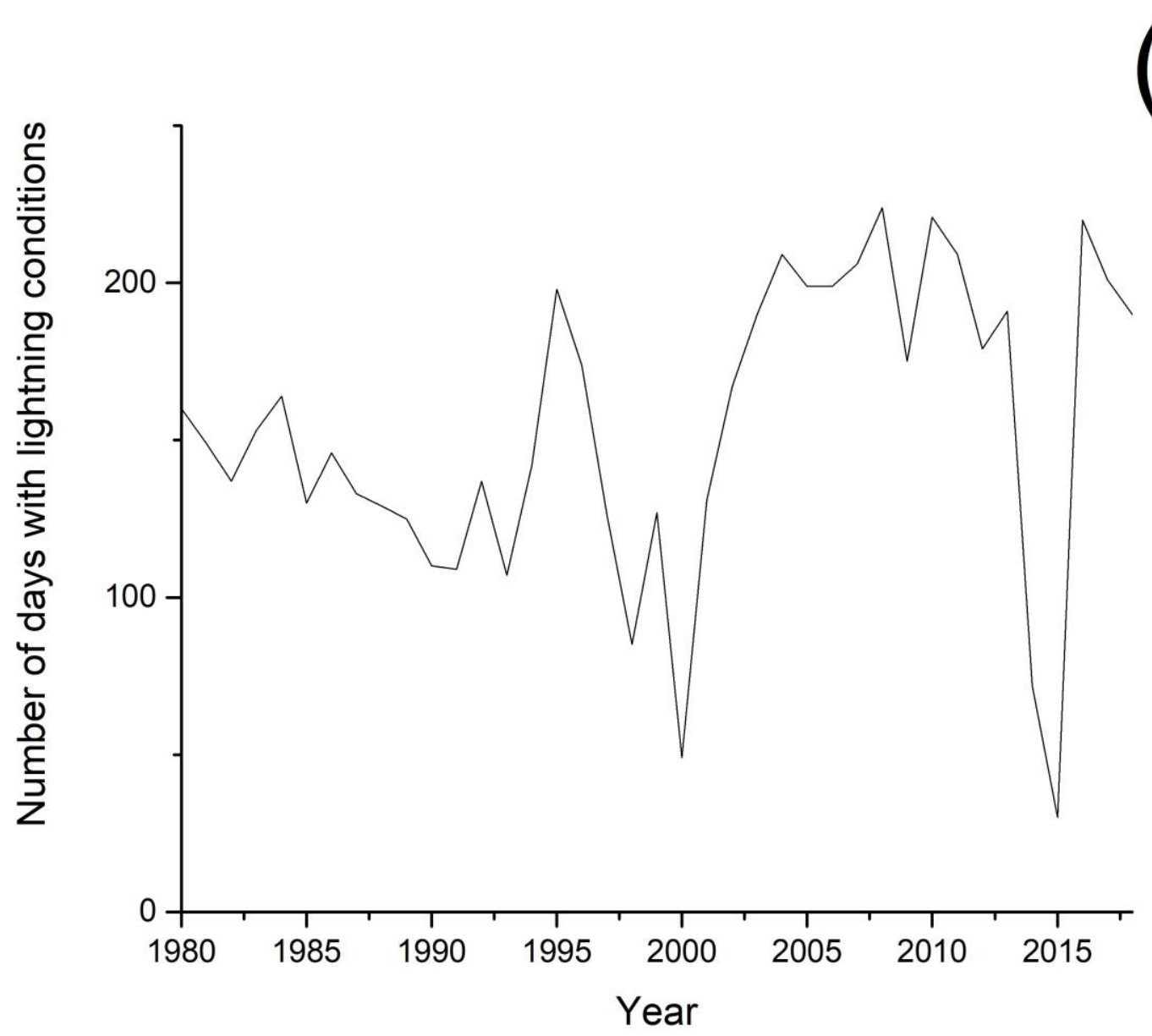

Fig. 1. Charts representing the number of days with cloud-to-ground lightning conditions in Romania (A), Hungary (B) and Bulgaria (C)

\section{CONCLUSIONS}

In this study, we investigated the number of days when lightning can occur and can affirm that according to the processing of the data provided by national eastern european weather stations following all the criteria aforementioned, we arrived at the conclusion of the fact that even though at certain times there can be a big variation from one year to the prior one regarding the number of days when this natural phenomena can occur, the overall number of days with lightning conditions and therefore a high probability for the cloud-to-ground lightning to appear stays in the same quotas during all the studied years.

\section{References}

1. Grießbach R., Naturgewalten - das Gewitter, epubli GmbH, Berlin, pp. 53-76, 2012. 
2. Goodman S. J., Blakeslee R. J., Koshak W. J., Mach D., Bailey J., Buechler D., Carey L., Schultz C., Bateman M., McCaul E., Stano G., The GOES-R Geostationary Lightning Mapper (GLM), Atmospheric Research, 125-126, pp. 34-49, 2013.

3. Workman E. J., Reynolds S.E., Electrical activity as related to thunderstorm cell growth, Bull. Amer. Meteor. Soc., 30, pp. 142-144, 1949.

4. Reynolds S. E., Brook M., Correlation of the initial electric field and the radar echo in thunderstorms, J. Meteor., 13, pp. 376-380, 1956.

5. Michimoto K., A study of radar echoes and their relationship to lightning discharge of thunderclouds in the Hokuriku District. Part II: Observation and analysis of "single-flash" thunderclouds in midwinter, J. Meteor. Soc. Japan, 71, pp. 195-204, 1993.

6. Bryan G. H., Fritsch J. M., Moist absolute instability: The sixth static stability state, Bull. Amer. Meteor. Soc., 81, pp. 1207-1230, 2000.

7. MacGorman D. R., Rust W.D., The Electrical Nature of Storms, Oxford University Press, New York, pp. 218-291, 1998.

8. Michimoto, K., A study of radar echoes and their relationship to lightning discharge of thunderclouds in the Hokuriku District. Part I: Observation and analysis of thunderclouds in summer and winter, J. Meteor. Soc. Japan, 69, pp. 327-335, 1991. 